\title{
Isolation and Identification of Three Bioactive Compounds from Endophytic Fungus Trichoderma sp.
}

\author{
Rashid Rahim Hateet \\ College of Pharmacy, University of Maysan, Maysan-Iraq. \\ Corresponding Author: biorashed@yahoo.com
}

\begin{abstract}
The endophytic fungus Trichoderma sp. was isolated from Ocimum basilicum L. plant and cultivated in the laboratory on potato dextrose agar PDA medium. Three bioactive chemical compounds were isolated and purified from culture of Trichoderma $s p$. using potato dextrose agar and potato dextrose broth. An investigation of the secondary metabolites by using Thin layer chromatography, column chromatography and Gas chromatography technique was carried out, The molecular weight of purified compounds 1,2 and 3 were $202 \mathrm{KD}, 137 \mathrm{KD}$ and $197 \mathrm{KD}$ respectively and chemical name of compound 1 is1,10-Decanedioic acid, chemical name of compound 2 is Phenol, 4-(ethylamino)-4-Ethylaminophenol and chemical name of compound3 is Pyrimido [5,4E]-1,2,4-triazine-5,7(4ah,6H)-dione,8,8a-dihydo-4a-hydroxy-6-methyl-. The antibacterial activity of the purified compounds against two bacterial species E.coli and $S$. aureus were tested by using a disc diffusion agar method reaching to $32,20 \mathrm{~mm}$ for compound 1and $24,19 \mathrm{~mm}$ for compound 2 and 27, 26mm for compound 3. The minimum inhibitory concentration (MIC) and minimum bactericidal concentration (MBC) values were determined by the standard serial dilution assay.

[DOI: 10.22401/JNUS.20.2.15]
\end{abstract}

Keywords: Bioactive compounds, Identification, Endophytic fungi, Antibacterial.

\section{Introduction}

Endophytes are microbes that colonize in internal tissues of plants without causing any immediate, negative effects [1]. Almost all vascular plant species appear to be inhibited by endophytic bacteria or fungi, these represent important components of microbial diversity. The relationship between the host plant and its endophyte shows symbiotic characteristics as the endophytic occupant usually obtains nutrients and protection from the host plant and in return profoundly enhances the fitness of the host by producing certain functional metabolites [2]. Fungal endophytes are a polyphyletic group of primarily ascomycetes fungi, whereas basidiomycetes, deuteromycetes and Oomycetes are rarely found [3]. Medicinal application of natural products can be traced back several millennia in human history. Natural products have been an integral part, in one form or another, of several indigenous therapeutic systems including traditional Chinese medicine [4]. Although they do not show host specifity, certain fungal lineages appear with greater frequency in plants representing particular families and thus denote host preference [5]. Between 1987 and 2000 approximately 140 new natural products were isolated from endophytic fungi [2]A similar number was subsequently characterized in half of this time span, i.e. between 2000 and 2006 [6]. Many of these exhibit interesting activity profiles. Cryptocin for example, is an tetramic acid isolated from the endophytic fungus Cryptosporiopsis quercina [7]. Endophyte Phomopsis sp. was isolated, which produces the antiinflammatory as well as antifungally and antibacterially active polyketide lactone and phenol [8].

\section{Materials and Methods \\ Isolation of endophytic fungus}

Healthy roots of Ocimum basilicum collected from Misan city south of Iraq and processed separately within $48 \mathrm{hrs}$ were of collection. The Root samples were surface sterilized [9]. Surface sterilized roots segments were equally spaced in Petri dishes on a potato dextrose agar medium (PDA) (medium was amended with chloramphenicol $150 \mathrm{mg}-\mathrm{l}$ ). The Petri dishes were closed by Para film and incubated at $27^{\circ} \mathrm{C}$ in a light space for $12 \mathrm{hrs}$ followed by $12 \mathrm{hrs}$ of dark cycles. The cultures were observed every day to check the growth of endophytic fungal in the roots O.basilicum. 


\section{Identification of endophytic fungi}

The identification of endophytic fungi was performed at the Microbiology Laboratory in the College of Science University of Misan., by means of analysis of macroscopic and microscopic characteristics of colonies.

\section{The test microorganisms}

The test bacteria used in this study were Esherichia coli as gram negative bacterium and Staphylococcus aureus as gram positive bacterium. All bacterial strains were obtained from the Microbiology Laboratory in the College of Science University of Misan.

\section{Preliminary screening of antibacterial assay}

The endophytic fungi were subjected to an antibacterial assay using a solid medium [10], which permits a rapid and qualitative selection of the bioactive microorganisms. Each endophytic strain was cultivated on the surface of PDA in Petri dishes, at $27{ }^{\circ} \mathrm{C}$, for 7 days. Then disks were cut from the PDA plate (6mm diameter) and transferred to the surface of Petri dishes previously spread with bacteria (Muller-Hinton agar, MHA).The Petri dishes were incubated at $37{ }^{\circ} \mathrm{C}$ for $24 \mathrm{hrs}$ Antibacterial activity was assayed by the measurement of inhibition diameter zones (IDZ).

\section{Extraction and purification of compounds}

The cultures of broth medium fungi were filtered on filter paper type Watmann No. 1, the filtrate was extracted 3 times using ethyl acetate $(1: 1 \mathrm{v} / \mathrm{v})$ using separating funnel [11]. Organic layer was collected then dehydrated with $\mathrm{Na} 2 \mathrm{SO} 4$ then placed in a Glass vial and dehydrated at $25 \mathrm{c}^{\circ}$. Thin layer chromatography (TLC) was applied for the isolation of extracted metabolites using silica gel(c-60) of $2 \times 10 \mathrm{~cm}$ and rate flow value (Rf) was measured. Purification of extracted compounds was made on silica gel (mesh 60) column chromatography $1.5 \times 50 \mathrm{~cm}$ using eluent methanol- ethyl acetate (1:1). A further purification of fractions was made by using another column $1.5 \times 50 \mathrm{~cm}$ and using eluent cyclohexane and ethyl acetate (1:1). The identification of the purified compounds was made using Gas chromatography (GC-Mass) technique.

\section{Antibacterial bioactivity assay}

Filter paper discs $(0.6 \mathrm{~mm})$ after being sterilized by autoclave were, socked in secondary metabolites solution for $5 \mathrm{~min}$, filter paper discs with extract were placed on the surface of Muller-Hinton agar medium in Petri-dishes streaked with $0.2 \mathrm{ml}$ of bacterial suspensions of bacteria strains. Plates were incubated at $37 \dot{\mathrm{c}}$ for $24 \mathrm{hrs}$, an appearance of inhibition zones around the filter paper disc indicating the bioactivity of secondary metabolites against tested bacteria [12]. The diameters of the clear zones were measured and compared with control agar plates containing discs with solvent only (control), triplicates were made.

\section{Minimum inhibitory concentration and minimum bactericidal concentration test}

The minimum inhibitory concentration (MIC) and minimal bactericidal concentration (MBC) values were determined by the standard serial dilution assay [13]. The inhibitory test was carried out on MullerHinton agar medium.

\section{Toxicity test}

Cytotoxicity of the fungal secondary metabolites was examined by using human $\mathrm{RBC}$ following a previously described method [14].

\section{Statistical analysis}

Data were analyzed using Analysis of Variance (ANOVA) between any pair of variables.

\section{Results and Discussion}

A total of 7 endophytic strains were isolated from roots of O.basilicum and subsequently submitted to a preliminary antimicrobial screening on solid medium. Isolation of endophytic fungi from medicinal plants produce bioactive compounds which have greater activity against various pathogenic microbes [15]. One endophytic isolate showed an activity against tested bacteria which was Trichoderma $s p$. Endophytic fungi are a good source for antimicrobial products [16]. Endophytes are reported as novel source of antimicrobial compounds [17]. Endophytic microorganisms are excellent sources of 
bioactive natural products that can be used to satisfy demand of pharmaceutical industry, since a single endophyte may be able to produce a variety of bioactive metabolites [18]. The production of Hypericin (C30H16O8), a naphthodianthrone derivative and Emodin (C15H10O5) believed to be the main precursor of hypericin [19].Isolation and purification of three compounds from Trichoderma sp. Mycelium were reported. Based on Gas chromatography (GC-mass) apparently the molecular formula of compound (1) is $\mathrm{C} 10 \mathrm{H} 18 \mathrm{O} 4$ with molecular weight $202 \mathrm{Kd}$ and its chemical name is1,10Decanedioic acid as show in Fig.(1), While the molecular formula of compound (2) is C8H11NO and its name is Phenol,
4-(ethylamino)-4-Ethylaminophenol with molecular weight $137 \mathrm{Kd}$ Fig.(2), and the molecular formula of compound (3) is C6H7N5O3 and its name is Pyrimido[5,4-E]1,2,4-triazine-5,7(4ah,6H)-dione,8,8a-dihydo4a-hydroxy-6-methyl-with molecular weight 197Kd Fig.(3).

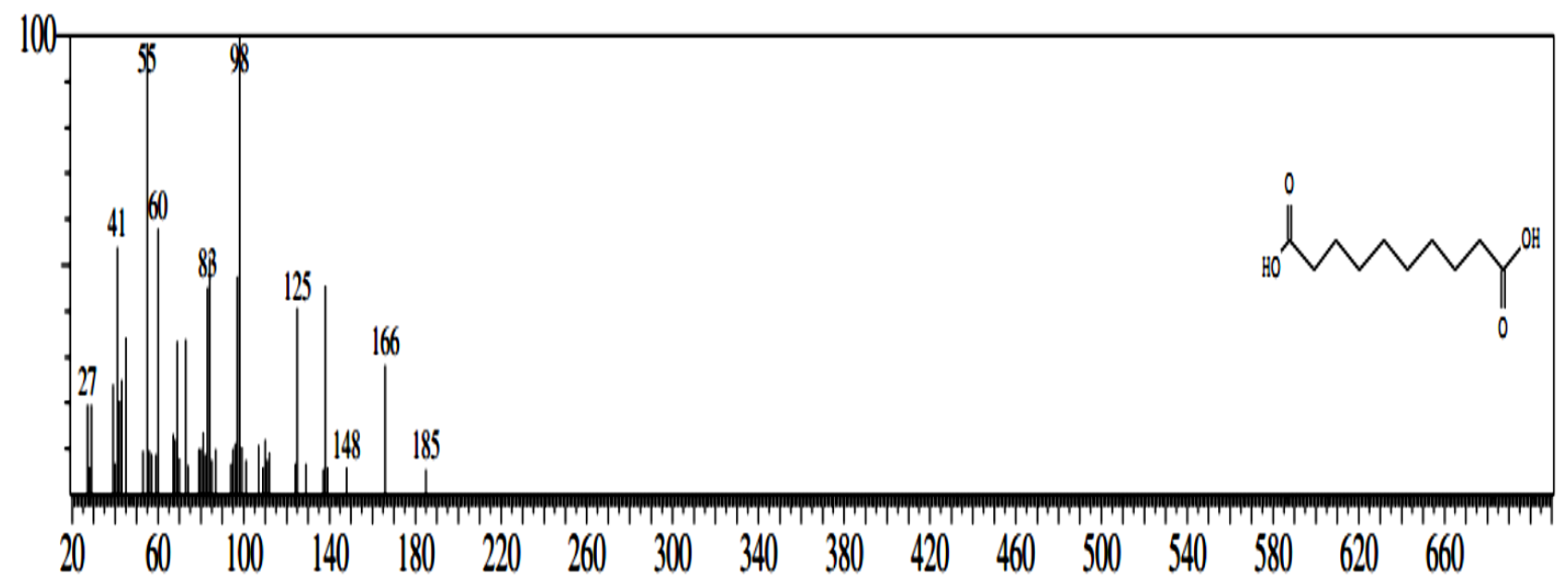

Fig.(1): Chemical structure and GC-Mass spectroscopy of compound 1,10-Decanedioic acid.

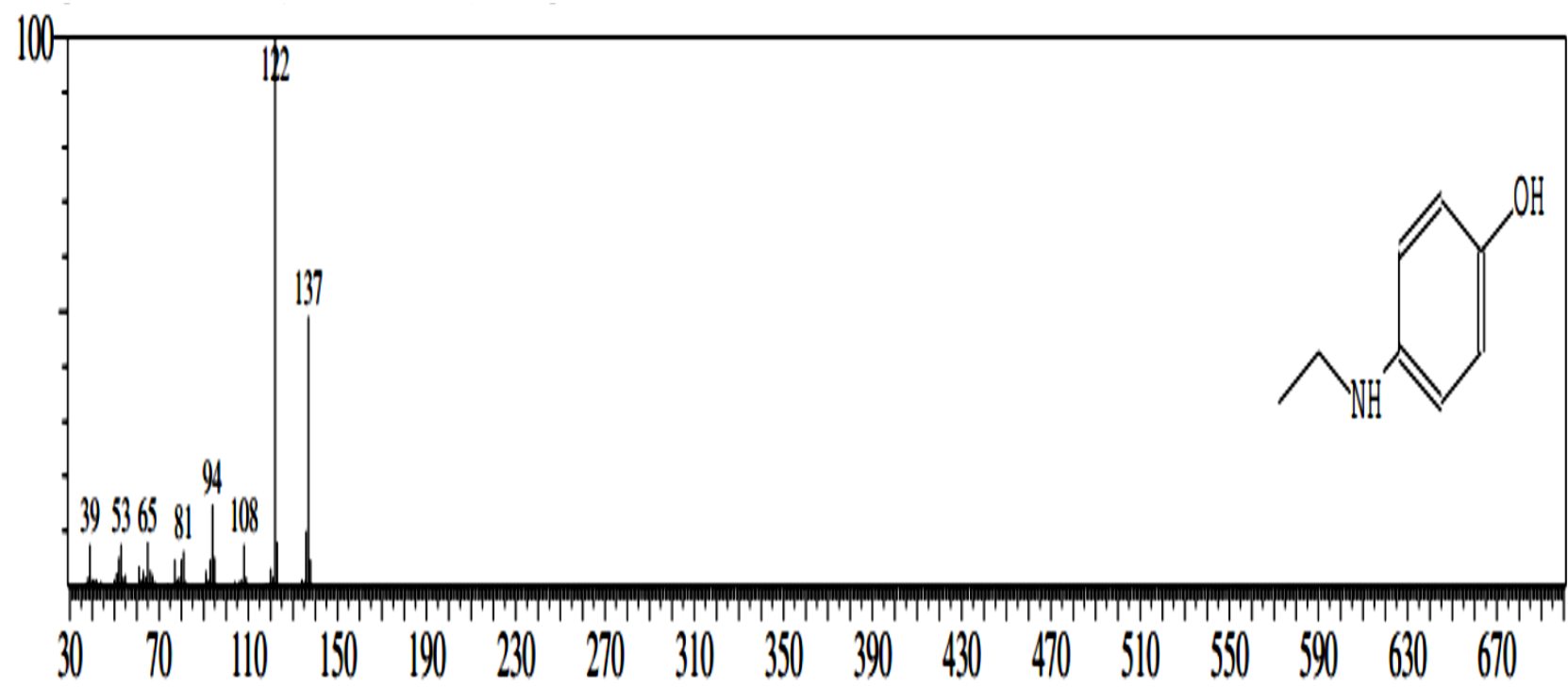

Fig.(2): Chemical structure and GC-Mass spectroscopy of compound Phenol, 4-(ethylamino)- 4-Ethylaminophenol. 


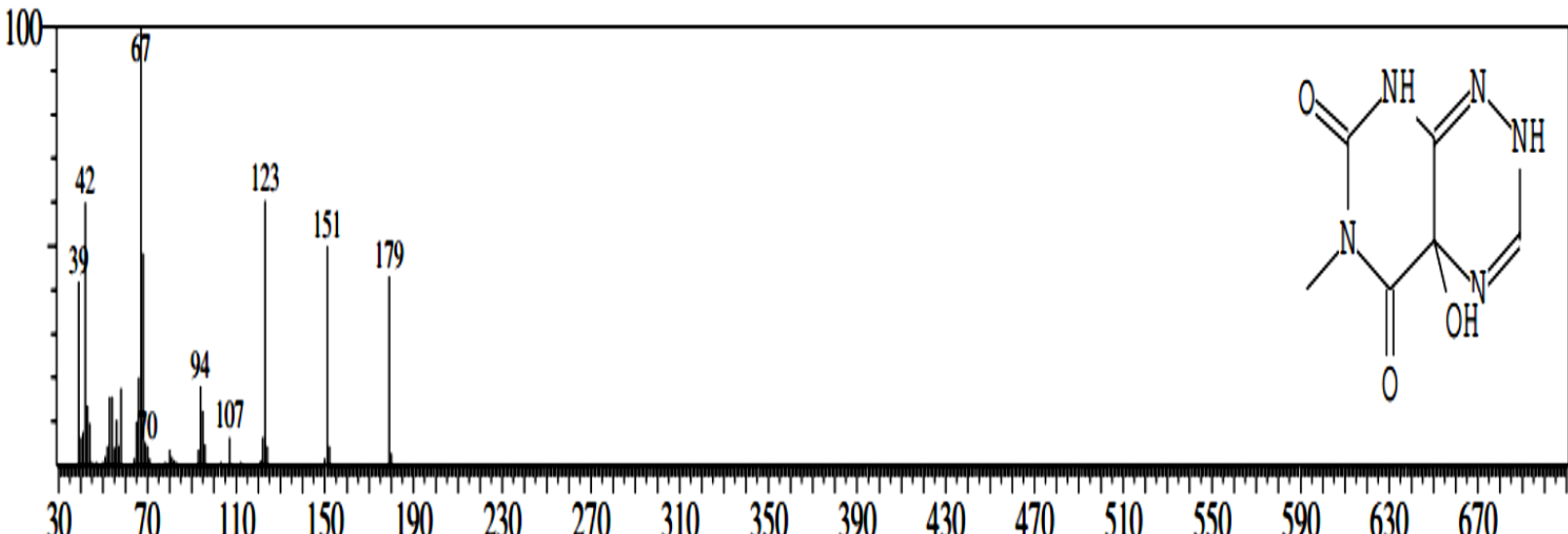

Fig.(3): Chemical structure and GC-Mass spectroscopy of compound Pyrimido[5,4-E]-1,2,4triazine-5,7(4ah,6H)-dione, 8,8a-dihydo-4a-hydroxy-6-methyl.

All purified compounds exhibited antibacterial activity against bacterial species. [15] Studied the antimicrobial potential of endophytic fungi Alternaria sp, Colletotrichum and Nigrospora and sterile mycelia isolated from the leaf tissues of Tectona grandis sp and Samanea saman.The inhibition zone diameter of compound (1) reached to 32 and $20 \mathrm{~mm}$ for $E$. coli and $S$. aureus respectively and 24 and $19 \mathrm{~mm}$ of compound (2) for bacterial species respectively and 27 and $26 \mathrm{~mm}$ of compound (3) Fig.(4). Purified compounds in the present study contained the active chemical groups. Other studies also indicated that 1,10 Decanedioic acid compound has antibacterial activity against bacteria[19]. Compounds1and 2 contained phenol, amino, hydroxyl and other groups identified as antimicrobial molecule. These biological activities are associated with the molecules structures, via their hydroxyl groups. The antimicrobial inhibitory impact of secondary metabolites can be related to the bioactivity of these compounds. It has been reported that several phenolic compounds including tannin are potent inhibitors of microbial enzymes [20]. Because phenolic compounds conjugate with proteins and bacterial membrane [21, 22]. The MIC and MBC are shown in Table (1). Since our study was the primary screening for the antibacterial activity of these extracts, assaying MIC is suggested in order to strengthen the findings of the current study[23].Varied values of MIC and MBC were obtained, the reason for this is due to the difference in the cell wall of gram negative bacteria and gram positive bacteria as it is characterized by a wall of negative bacteria lack the permeability of the outer shell of antibiotics because of the presence of the outer layer, which prevents the arrival of antibiotics to the target zone. The wall of gram negative bacteria contains on lipopolysaccharides and lipoprotein and the walls of gram positive bacteria are characterized by permeability for effective compounds more than gram negative bacteria [24].

Table (1)

The minimal inhibitory concentrations (MIC) and minimal bactericidal concentrations (MBC) of purified three compounds $(\mathrm{mg} / \mathrm{mL})$ Compounds.

\begin{tabular}{|l||c|c||c||c||}
\hline \multicolumn{1}{|c||}{} & \multicolumn{2}{c|}{ E.coli } & \multicolumn{2}{c|}{ S.aureus } \\
\hline Compounds & MIC & MBC & MIC & MBC \\
\hline \hline Compound 1 & 6.25 & 12.5 & 3.12 & 6.25 \\
\hline Compound 2 & 3.12 & 6.25 & 6.25 & 12.5 \\
\hline Compound 3 & 6.25 & 12.25 & 6.25 & 12.5 \\
\hline
\end{tabular}

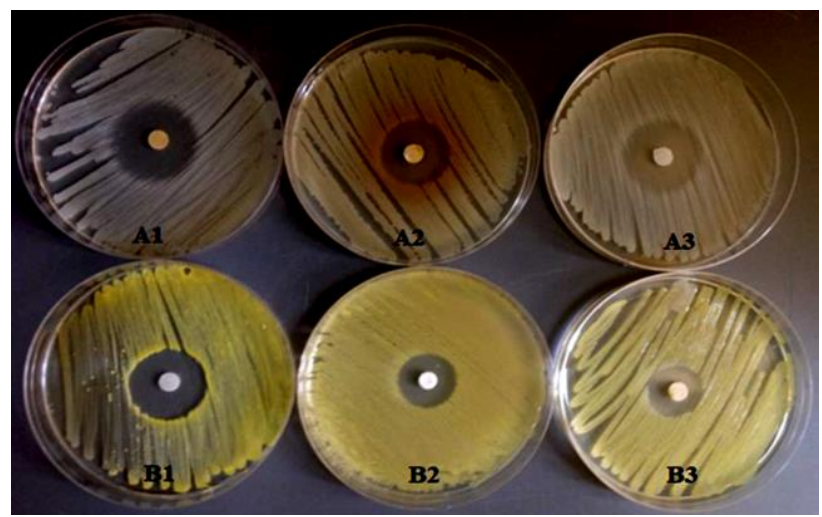

Fig.(4): Inhibition zone diameter (mm): 1: compound NO. (1), 2: compound NO.(2) and 3: compound NO.(3). 


\section{Conclusion}

Endophytic fungi have proven to be rich sources of novel natural compounds with a wide spectrum of biological activities. This study revealed that this endophytic fungus showed a significant antibacterial activity.

\section{References}

[1] Bacon C. W., White, J. F., "Microbial Endophytes", Marcel Dekker inc. New York, 2000.

[2] Tan RX, Zou WX., "Endophytes: A rich source of functional metabolites. Nat Pro Re.; 18: 448-459, 2001.

[3] Arnold A. E., "Understanding the diversity of foliar endophytic fungi: progress, challenges, and frontiers". Fungal Biology Reviews 2, 51-66, 2007.

[4] Liu Y., Yang, L., "Early metabolism evaluation making traditional Chinese medicine effective and safe therapeutics". Journal of Zhejiang University 7, 99-106, 2006.

[5] Cannon P. F., Simmons, C. M., "Diversity and host preference of leaf endophytic fungi in the Iwokrama Forest Reserve, Guyana”. Mycologia 94 (2), 210-220, 2002.

[6] Zhang P.; Zhou, P., P.; Jiang, C.; Yu. H,: $\mathrm{Yu}$ L. J., "Screening of Taxol-producing fungi based on PCR amplification". Biotechnol. Lett. 30 (12), 2119-2123, 2008.

[7] Li J. Y.; Strobel, G.; Harper, J.; Lobkovsky, E.; Clardy, J.," Cryptocin, a potent tetramic acid antimycotic from the endophytic fungus Cryptosporiopsis cf". quercina. Org. Lett. 2(6)767-770, 2000.

[8] Weber D.; Sterner, O.; Anke, T.; Gorzalczancy, S.; Martino, V.; Acevedo, C. Phomol, "a new anti-inflammatory metabolite from an endophyte of the medicinal plant Erythrina crista-galli". $J$. Antibiot. 57(9), 559-563, 2004.

[9] Suryanarayanan T.S., Kumaresan,V. \& Johnson, J.A. ,"Foliar fungal endophytes from two species of the mangrove Rhizophora". Canadian Journal of Microbiology 44: 1003-1006, 1998.

[10] Nogueira M.A., Diaz,G., and Stangarlin, J.R., "Search of antibiotic Metabolites from phytopathogenic fungi". Latin American J. Pharma.26:741-743, 2007.
[11] Zur E.m "Isolation, Structure determination and biological activity assessment of secondary metabolites from marine -derived fungi". Ph.D. thesis. Von cludia Osterhage. 186 pp, 2001.

[12] Casals J. B., "Tablet sensitivity testing on pathogenic fungi". Journal of clinical pathology, 32: 719-722, 1979.

[13] McGinnis, M., "RLaboratory Handbook of Medical Mycology", Academic Press, New York, 1980.

[14] Xian-guo H. and Ursula, M., "Antifungal compound from Solanum nigrescens". J. Enthopharm. 43: 173-177, 1994.

[15] Sukanyanee C, Piapukiew J, Thienhirun $S$, Sihanonth $\mathrm{P}$ and Whalley AIS., "Endophytic Fungi of Teak leaves Tectona grandis L. and rain tree leaves Samanea saman Merr". World J Microbiol Biotechnol; 22:481-486, 2006.

[16] Mousa W. K., and Raizada, M. N., "The diversity of anti-microbial secondary metabolites produced by fungal endophytes: an interdisciplinary perspective". Front. Microbiol. 4:65. doi: 10.3389/fmicb.2013.00065, 2013.

[17] Strobel G. A. and Daisy, B., "Bioprospecting for Microbial Endophytes and Their Natural Products". Microbiol. Mol. Bio. Rev. 67(4):491-502, 2003.

[18] Santos IP, Silva NL, Silva MV, Araujo JM, Cavalcant MSI, Lima VM., "Antibacterial activity of endophytic fungi from leaves of Indigofera suffruticosa Miller (Fabaceae) Front". Microbial .J. PubMed; 6:350, 2015.

[19] Kusari S and Spiteller M., "Are we ready for industrial production of bioactive plant secondary metabolites utilizing endophytes". Nat Prod Rep; 28:1203-1207, 2011.

[20] Kamba A. S.; Hassan, L. G., "Phytochemical screening and antimicrobial activities of Euphrobiabalasamifera leaves, stems and roots against pathogenic microorganisms". Afr. J Pharmaceutical Sic and Pharmacology 15:57-64, 2010.

[21] Zongo C., A. Savadogo, K.M. Somda, J. Koudou and A.S. Traore., "In vitro evaluation of the antimicrobial and antioxidant properties of extracts from whole plant of Alternanthera pungens H.B. 
$\& \mathrm{~K}$. and leaves of Combretum sericeum G. Don". International Journal of Phytomedicine, 3: 182-191, 2011.

[22].Zare, M. Z., Rohani, S. M. R., Raeisi, M., Hosseini, S. J. and Hosseini, M., "Antibacterial Effects of Monolaurin, Sorbic Acid and Potassium Sorbate on Staphylococcus aureus and Escherichia coli". J. Food Qual. HazardsControl.1 (2):52-55, 2014.

[23] Ramasamy K., Lim S.M., Bakar H.A., Ismail N., Ismail, M.S.; Ali, M.F.; Weber, J.F.F and Cole E., "Antimicrobial and cytotoxic activities of Malaysian endophytes". Phytother Res. 24(5): 640643, 2010.

[24] Chandrashekhara S., "Isolation and characterization of antibiotic production from soil isolates by fermentation". Ph.D. thesis, Vinayaka Missions University, India, 2010. 